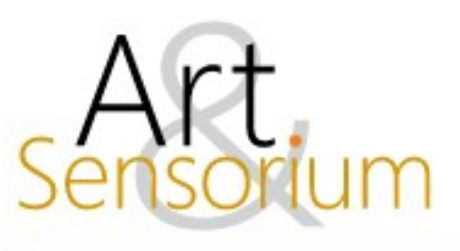

\title{
A ORIGINALIDADE DE JOSÉ GUADALUPE POSADA: UM EXAME DE TERRIBLE Y VERDADEIRA NOTICIA (1910)
}

https://doi.org/10.33871/23580437.2021.8.1.061-080

Leonardo Bento de Andrade ${ }^{1}$

\begin{abstract}
Resumo: O presente artigo pretende realizar uma análise da obra Terrible y verdadeira noticia (1910) do gravador mexicano José Guadalupe Posada (1852-1913). Em 1930, Diego Rivera ressaltou o caráter original e distante da imitação da obra de Posada, colocando-o como um exemplo para os artistas mexicanos do século XX. Contudo, através duma ótica warburguiana, atenta às anacronias e sobrevivências das imagens, nota-se como, a partir da sobrevivência dum mesmo gesto na história da arte, é possível tensionar o discurso do muralista. A originalidade da obra de Posada não está vinculada à questão da imitação, pelo contrário, ela é um elemento presente e enriquecedor da sua produção. Para auxiliar nessa tarefa, valemo-nos dos escritos de Aby Warburg, Walter Benjamin, Gertrud Bing e Georges Didi-Huberman.
\end{abstract}

Palavras-chave: Aby Warburg; Diego Rivera; José Guadalupe Posada; Originalidade; Sobrevivências.

\section{THE ORIGINALITY OF JOSÉ GUADALUPE POSADA: AN EXAMINATION OF TERRIBLE Y VERDADEIRA NOTICIA (1910)}

\begin{abstract}
This article aims to analyze the work Terrible y verdadeira noticia (1910) by the Mexican engraver José Guadalupe Posada (1852-1913). In 1930, Diego Rivera emphasized the original and distant character of the imitation of Posada's work, setting him as an example for Mexican artists of the 20th century. However, through a Warburguian perspective, attentive to the anachronies and survivals of images, it can be seen how, from the survival of the same gesture in art history, it is possible to tension the muralist's discourse. The originality of Posada's work is not linked to the issue of imitation, on the contrary, it is a present and enriching element in his production. To assist in this task, we used the writings of Aby Warburg, Walter Benjamin, Gertrud Bing and Georges DidiHuberman.
\end{abstract}

Keywords: Aby Warburg; Diego Rivera; José Guadalupe Posada; Originality; Survivals.

\footnotetext{
${ }^{1}$ ORCID: https://orcid.org/0000-0001-8459-566X. Universidade Federal do Paraná (UFPR) - Curitiba, Paraná, Brasil. Email:andradelb@hotmail.com.
} 


\title{
LA ORIGINALIDAD DE JOSÉ GUADALUPE POSADA: UN EXAMEN DE TERRIBLE Y VERDADERA NOTICIA (1910)
}

\begin{abstract}
Resumen: Este artículo tiene como objetivo analizar la obra Terrible y verdadera noticia (1910) del grabador mexicano José Guadalupe Posada (1852-1913). En 1930, Diego Rivera enfatizó el carácter original y distante de la imitación de la obra de Posada, poniéndolo como ejemplo para los artistas mexicanos del siglo XX. Sin embargo, a través de una perspectiva warburguiana, atenta a las anacronías y supervivencias de las imágenes, se puede ver cómo, a partir de la pervivencia del mismo gesto en la historia del arte, es posible tensar el discurso del muralista. La originalidad de la obra de Posada no está ligada al tema de la imitación, al contrario, es un elemento presente y enriquecedor en su producción. Para ayudar en esta tarea, usamos los escritos de Aby Warburg, Walter Benjamin, Gertrud Bing y Georges Didi-Huberman.
\end{abstract}

Palabras Clave: Aby Warburg; Diego Rivera; José Guadalupe Posada; Originalidad; Superviviencias.

\section{Introdução}

A obra do gravador e ilustrador mexicano José Guadalupe Posada (1852-1913) é vasta e ampla. Ao longo dos seus 42 anos de vida profissional, calcula-se que produziu milhares de gravuras que iam desde rótulos para carteiras de cigarro até ilustrações para periódicos. Embora tenha sido profissionalmente ativo desde 1871, a maior parte da sua produção que sobreviveu até nossos dias é da virada do século XX, quando trabalhou na capital mexicana. A preservação da sua obra, impressa normalmente em papéis baratos e de baixa qualidade, deve-se à Casa Editorial Arroyo, a qual usou as suas matrizes por mais de uma década após a sua morte e, principalmente, ao esforço conjunto de alguns grupos progressistas formados em meados de 1920, que trouxeram a sua vida e obra para o debate público após quase uma década da sua morte.

A partir de 1921, uma intelligentsia composta, grosso modo, por profissionais financiados de forma direta ou indireta pelo governo de Álvaro Obregón começou a tomar forma. O Muralismo nasceu, imprimindo nas paredes dos prédios públicos cenas messiânicas de união nacional enquanto antropólogos, etnólogos e fotógrafos foram enviados aos quatro cantos do país em busca da mexicanidade justificadora da existência duma nação moderna. Porém, apenas em 1925 Posada foi descoberto e elevado à categoria de pai da arte popular mexicana por artistas como Diego Rivera, José Clemente Orozco, Jean Charlot e, posteriormente, por Leopoldo Méndez.

Rivera foi um dos mais ativos e bem sucedidos propagadores da ideia de que Posada teria sido um artista com uma obra totalmente original e livre de qualquer imitação. No entanto, a afirmação do pintor opera menos como uma peça no processo de resgate da obra do gravador e mais como um dos vários passos na justificação dos esforços reformadores do Estado pós-revolucionário. Por meio duma abordagem que toma como referência o aparato gnosiológico do historiador da arte Aby Warburg, notamos como a originalidade da obra de Posada não está em nada alinhada à concepção de Diego Rivera.

A obra posadiana - cujo escopo é reduzido neste texto ao exame iconográfico de uma única gravura das centenas que sobreviveram até a nossa época — é permeada pela imitação. O que não é de forma alguma um demérito, e sim uma grande oportunidade para demonstrar a pertinência do trabalho de Warburg para o desmonte, neste caso em específico, do discurso populista-nacional no México do século XX. 


\section{Origem e originalidade}

Nas páginas da história da arte e do direito, uma anedota descrita por Giorgio Vasari evolvendo Marcantonio Raimondi e Albrecht Dürer é famosa. Marcantonio foi um exímio gravador italiano que costumeiramente se baseava em obras de outros artistas ou as reproduzia ipsis litteris e Dürer, seu contemporâneo, era um dos mais renomados do seu meio e angariava apreciadores também ao sul dos Alpes. Na primeira década do século XVI, quando publica uma série sobre a Paixão de Cristo, Marcantonio as reproduz inclusive com o famoso monograma do autor (AD). A boa intenção do italiano ao indicar a autoria das imagens não conseguiu agradar a Dürer, que apelou à Signoria de Veneza, uma ação que apenas lhe concedeu direitos sobre o uso da sua assinatura (VASARI, 2011, 1. 1087). Por que Dürer não conquistou integralmente os direitos sobre as reproduções comercializadas pelo italiano? Vasari não nos dá mais detalhes sobre o caso, mas um simples olhar para o original e para a cópia nos revela um possível motivo. Embora ambas sejam semelhantes, a cópia possuí atributos de Marcantonio, uma marca que somente sua "maneira" — para ficarmos em Vasari — poderia imprimir no objeto.

O caso "Dürer contra Marcantonio" apresenta ao menos dois elementos interessantes para a nossa análise. O primeiro é a questão do distanciamento das cópias dos seus originais, não numa dimensão qualitativa, mas quanto às suas diferenças. Para Walter Benjamin, cada cópia é única dada a singularidade da condição a qual veio ao mundo (BENJAMIN, 1987, p. 167). Portanto, a barreira entre o original e o imitado se encontra borrada pelo progresso técnico humano, a imagem original inexiste na medida em que as suas reproduções são autoafirmativas, dotadas da sua própria autenticidade e totalmente diferentes nas suas semelhanças. Já o segundo, está relacionado à condição da imitação como um objetivo para as produções artísticas.

A discussão sobre originalidade na História da Arte se situa junto ao processo de estruturação da área do conhecimento. A busca por referenciais na Antiguidade foi uma operação compartilhada por Marcantonio e Dürer, uma característica marcante do Renascimento e retomada de forma explícita no neoclassicismo. Winckelmann, considerado por muitos o pai fundador da disciplina, pensava-a incumbida do desvelamento da origem e da trajetória do objeto artístico, contemplando o seu nascimento, desenvolvimento e decadência (WINCKELMAN, 1873, p. 149-150), uma percepção que, no Século das Luzes, marcado pelo kantianismo intrínseco às ciências modernas - lugar aspirado tanto pela História da Arte quanto pela História - , serviu como um instrumento adequado para disciplinar um campo ainda selvático. Assim, o fluxo das artes, que poderia seguir o seu curso à sanha dos aclives, declives e sumidouros proporcionados pela uniformidade do seu leito temporal, foi canalizado pela tecnicidade disciplinaria da arqueologia-teleológica winckelmanniana. Além disso, séculos antes do historiador da arte alemão, Vasari já havia apresentado a sua percepção acerca de um processo de desenvolvimento e ascensão da arte no prefácio à terceira parte de seu Vidas dos artistas (1568).

Vasari pensa a morte e ressurgimento da Antiguidade nos séculos XV e XVI, deixando de pressupor o seu esgotamento definitivo, opondo-se à trajetória parabólica qualitativa dos estilos artísticos imaginada por Winckelmann, enquanto julga a qualidade dos seus pares baseada na capacidade de transposição da perfeição natural, a imitação era um objetivo e não um pecado (VASARI, 1998, p. 277-279). Winckelmann, corroborando com a declaração do estudioso aretino, toma a imitação da arte dos antigos como o único meio de redimir a arte dos modernos, fruto de uma prática mais preocupada com os exageros do que com o requinte da beleza material (WINCKELMAN, 1972, p. 61). Se a mimese aristotélica era um aspecto central nas produções artísticas para ambos, o estatuto da obra de arte no que tange à originalidade não tomava a cópia da arte antiga e da natureza como um tabu — até porque toda a busca por uma imagem original é vã. 
Walter Benjamin, no seu ensaio sobre o teatro alemão, nos fala justamente da impossibilidade distintiva imbricada na relação original-cópia. A Origem (Ursprung) não é a gênese, mas a cristalização (sobrevivência) do momento de formação do originário que permeia a história. Inexiste um ponto original, mas sim uma constelação de estruturas translúcidas, monádicas, capazes de desvelar o seu brilho em certos momentos históricos (BENJAMIN, 2020, p. 34-35). Para Benjamin,

A ideia é uma mônada. O ser que nela penetra com a sua pré e pós-história mostra, oculta na sua própria, a figura abreviada e ensombrada do restante do mundo das ideias, tal como nas mônadas do Discurso sobre a metafisica, de 1686: em cada uma delas estão indistintamente presentes todas as demais. A ideia é uma mônada - nela repousa, preestabelecida, a apresentação dos fenômenos como sua interpretação objetiva (BENJAMIN, 2020, p. 36).

Ou seja, cada um desses fragmentos de memória é dotado da potência significadora dum mundo próprio. Benjamin aplicou sistematicamente a ideia de mônada no livro das Passagens, algo que, em última instância, desagradou a Theodor Adorno. Ele chamou de "ilação imediata" a leitura benjaminiana do efeito das leis do vinho sobre a subjetividade de Baudelaire numa troca de cartas ao final de 1938. Para o filósofo de Frankfurt, $A$ alma do vinho (1861) de Baudelaire é um reflexo dum processo global alheio aos anseios subterrâneos da psique ou, nas palavras dele, das "evocações mágicas materialístico-historiográficas" de Benjamin. Este, rebateu dizendo que seu objetivo não era pensar o problema do imposto, mas o "significado da embriaguez para Baudelaire" (AGAMBEN, 2008, p. 134-138). Portanto, Benjamin não se preocupava com o desenvolvimento teleológico do seu objeto de estudo, mas como ele atuava em diferentes - e determinadas — situações. O que importa para Benjamin é o efeito de Baudelaire na lei e não o da lei em Baudelaire. Essa espécie de afloração - ou lampejo - ocorre nos vacilos da memória individual e só têm sentido nos seus desdobramentos na materialidade do mundo sensível (BENJAMIN, 2009, p. 504). Cada um deles é uma origem que só faz sentido na historicidade do seu momento de emergência e, ao fazem isso, tornam o fluxo devir nada retilíneo e permeado por turbilhões.

O modelo vórtico indica justamente uma cesura, fratura, no devir — afinal, sprung é "salto" e também "cisão". Uma cisão no "solo das doutrinas estéticas" causada pelo aspecto anacrônico da origem (DIDI-HUBERMAN, 2015, p. 95-96). A imagem dialoga dialeticamente com a sua origem, é uma síntese inacabada do sincrônico e do diacrônico e não uma estruturação produzida gradativamente no contínuo do tempo cuja gênese pode ser rastreada, registrada e dotada de sentido. Portanto, a origem por si só não fornece respostas e nem fomenta perguntas.

Essa discussão quanto a validade da imitação e da originalidade se encontrava latente não apenas no Velho Mundo de Benjamin, Winckelmann e Vasari. Apenas dois anos após a publicação da versão revisada de Origem do drama trágico alemão (1928), encontramos na principal antologia do gravador José Guadalupe Posada uma ode ao caráter original do seu trabalho.

Em 1930, no México, a antropóloga Frances Toor publica, junto do editor Blas Vanegas Arroyo e do artista Paul O’Higgins, Monografia: las obras de José Guadalupe Posada. O compilado de 406 gravuras atribuídas a Posada vem na esteira do processo de reconstrução da imagem pública do México pós-revolução de 1910. A partir de 1921, o Ministro da Educação do governo Álvaro Obregón, José Vasconcelos, capitania um projeto cultural de criação duma identidade nacional transmissora de estabilidade política e união popular (EDER, 1990, p. 105-106). Os programas de fomento do governo financiaram diversos profissionais empenhados na construção do perfil do novo México. Nesse contexto, por exemplo, surge o Muralismo mexicano, cujo início foi muito influenciado pelas ideias redentoras do ministro. 
Monografia é um dos vários projetos paralelos às políticas de fomento estatal. Ela conta com um prefácio de Toor e com uma introdução de Diego Rivera. Este, faz do texto um chamado à monumentalização de Posada, chama-o de "gravador genial e incomparável" e de "artista revolucionário" por ser dono duma produção "livre da sombra de qualquer imitação, com um acento mexicano puro" e por ter sido um percursor dos revolucionários de 1910, um retratista do cotidiano do povo mexicano e critico dos excessos das elites (RIVERA, 2012, p. iii-v). Já Toor, no seu lugar de pesquisadora e editora da Mexican Folkways (1925-1937) — uma das maiores revistas etnográficas da época — , fornece ao leitor alguns dados biográficos do gravador e relata a existência duma relação de admiração e amizade entre ele e o jovem Rivera (TOOR, 2012, p. i-ii). Por meio desse arranjo, reiterado na sua autobiografia de 1960, o muralista assume o papel dum aprendiz informal e, por conseguinte, herdeiro do legado de Posada, o qual teria sido uma forte influência durante os seus anos de formação acadêmica (MARCH; RIVERA, 1963, p. 35-36).

O muralista também traz o seu mestre para a sua produção artística. No mural Sueño de una tarde dominical en la Alameda Central (1947), ele retrata-se numa forma juvenil junto de Posada, sinalizando uma relação de proximidade e respeito para com ele. A situação repete-se mais uma vez no esboço nunca executado intitulado Merchant of Art (1955) - disponível no acervo do Detroit Institute of Arts. Nele, Rivera parece retratar uma suposta cena do seu período de formação, onde uma jovem versão de si observa o trabalho do gravador experiente enquanto o coroa com o título de "o maior artista do povo mexicano".

É pela originalidade que Rivera toma a obra e a figura de Posada como baluarte da arte mexicana, como um artista capaz de expressar as emoções do povo mexicano. Contudo, a figura do artista original enjeitado pelos seus contemporâneos academicistas apresenta fragilidades. A pureza da obra do gravador inexiste, ela está permeada pela imitação e manchada pelo tempo, como o exemplo um tanto anedótico, é verdade - do exame de uma de suas centenas das gravuras nos mostra.

\section{Deusa, santa e camponesa}

Posada produziu gravuras com os mais diversos temas enquanto trabalhava na capital mexicana de 1888 até a sua morte, em 1913. Elas serviam, majoritariamente, para ilustrar corridos - canções e poemas impressos em volantes - com os mais diversos temas. Os relatos de casos insólitos eram os mais populares, como o corrido Terrible y verdadera noticia del espantoso ejemplar ocurrido con Norberta Reyes, que cerca de la ciudad de Zamora (Figura 1), que apresenta a trágica história da parricida Noberta Reys. Segundo o texto que acompanha a gravura, Norberta, filha unigênita de Anselme e Pascuala, desde pequena demonstrou um gênio impetuoso não coibido pelos pais. $\mathrm{O}$ resultado dessa má criação foi uma jovem temperamental, repleta de caprichos e tão impulsiva que não titubeou em matar o casal durante a noite. 


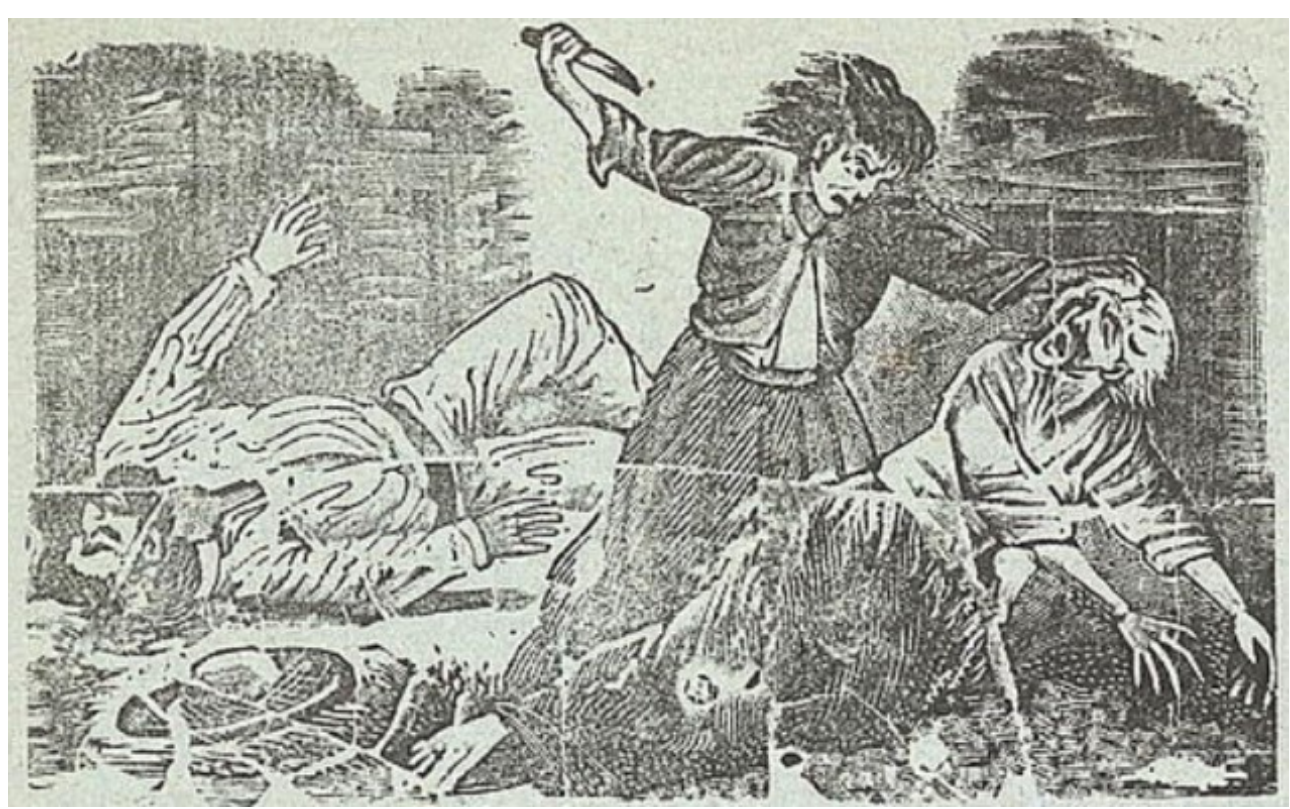

Figura 1 - José Guadalupe Posada. Gravura de Terrible y verdadera noticia del espantoso ejemplar ocurrido con Norberta Reyes, que cerca de la ciudad de Zamora (1910). Fonte: Acervo da Library of Congress.

No corrido, o ilustrador retratou o momento do assassinato da mãe, cujos cabelos a filha segura enquanto prepara o golpe fatal com a faca, já suja pelo sangue do seu pai. Norberta aparece em pé, de braços abertos, empunhando a arma com tamanha força que a sua mão e punho direitos se contraem vigorosamente para acompanhar a ação. A sua perna direita, um pouco afastada do restante do seu corpo, é um sinal do alastramento da agitação violenta, não limitada ao movimento dos membros superiores. Ela partiu daquela posição para desferir o golpe, um movimento cuja execução necessita do acompanhamento do restante do corpo, inclusive da face.

As expressões faciais são um ponto à parte na composição da gravura. O rosto de Norberta surge contorcido pelo furor colérico, os olhos arregalados, a boca aberta, as sobrancelhas arqueadas e o movimento do cabelo contrastam com a serenidade do cadáver do pai e com o terror expresso pela pele flácida do rosto da mãe. Posada representa a parricida como figura dominadora, num embate totalmente desigual com Pascuala, figura esquálida e com cabelos brancos, que, debilitada pela idade, não ousa se defender.

A qualidade do trabalho de Posada é inegável, tanto os recursos utilizados para solucionar os problemas de representação da cena quanto à técnica empregada está alinhada a um profissional com quase quarenta anos de experiência em 1910. Contudo, a sua arte está longe de possuir a pureza e a originalidade atribuída por Rivera. Já encontramos uma fórmula corporal e sentimental do movimento de Norberta numa cratera ática do século V a. C., decorada com uma Amazonomaquia (Figura 2). 


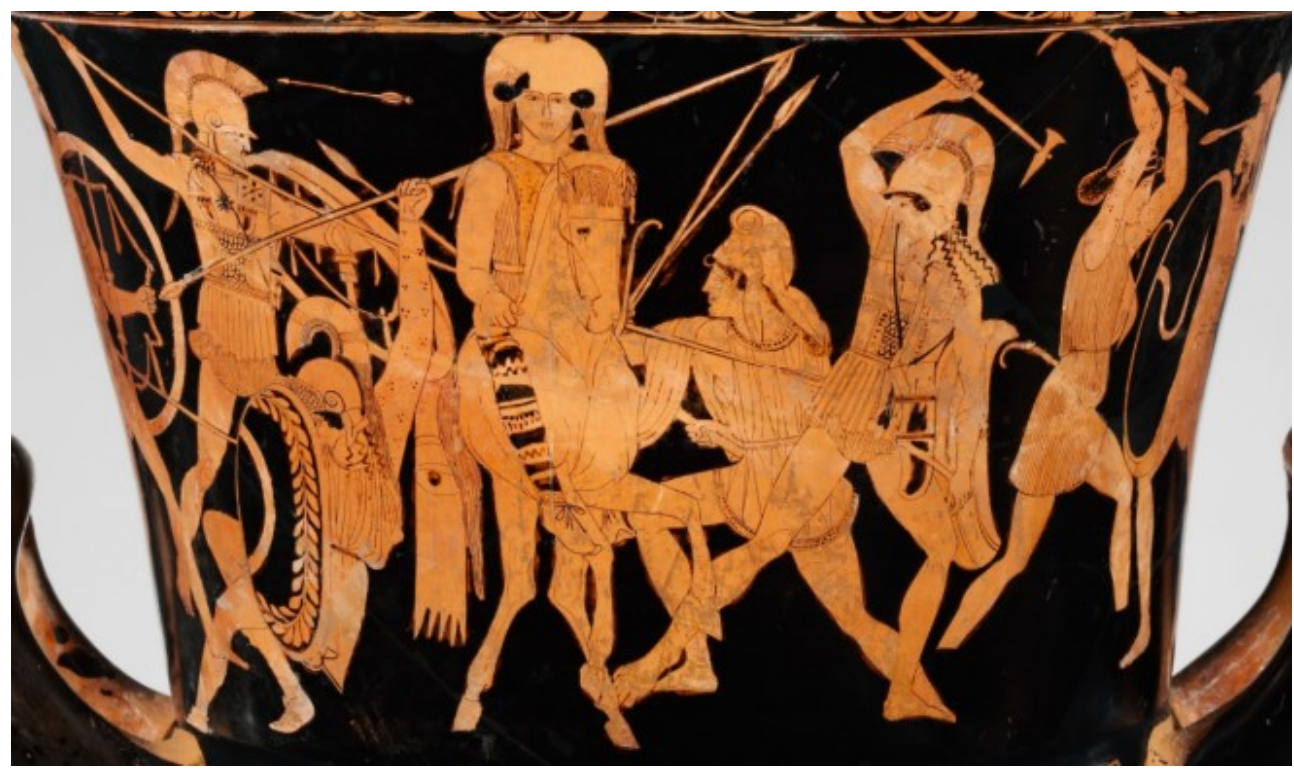

Figura 2 - Pintor de Berlim. Detalhe de Amazonomaquia (c. 460-450 a.C.). Terracota. Fonte: Acervo do Metropolitan Museum of Art.

As cenas da subjugação das invasoras Amazonas por soldados atenienses são recorrentes na arte ática do quinto e quarto século antes de Cristo. O tema representa a vitória, ainda que custosa, sobre os adversários estrangeiros, o triunfo da civilização sobre a barbárie (TARBELL, 1920, p. 229). Em meio à desordem da batalha, onde os dois lados se digladiam com lanças, machados, espadas e escudos, um dos envolvidos nos chama a atenção por sua postura semelhante à da jovem retratada por Posada.

O soldado grego em questão, localizado na porção direita da peça, é retratado golpeando uma adversária no flanco direito. Ele vale-se de uma lança longa para desferir o ataque, empunhando-a com o braço direito, cujo cotovelo se encontra levemente flexionado, enquanto projeta o seu corpo em direção ao alvo, assim potencializando a força do golpe.

A afinidade entre o movimento do soldado grego e o de Norberta não se limita a uma influência direta da pintura sobre a obra de Posada, ela pode ser sistematizada menos à filogenética e mais a um conjunto constelatório. Ou seja, não se trata da exatidão positivista das ciências naturais - ou do estilo - , onde as afinidades dos objetos ocorrem apenas através dos seus ancestrais diretos, mas de uma abordagem rizomática-psíquica capaz de propiciar leituras dinâmicas conforme o interesse do observador. É com esse olhar que notamos uma configuração motiva semelhante ao caso grego e mexicano presente numa gravura de Andrea Meldola (Figura 3). 


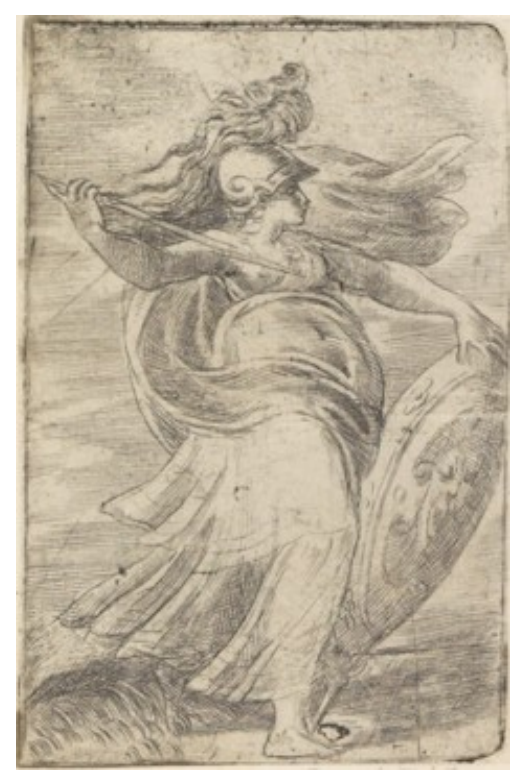

Figura 3 - Andrea Meldola. Bellona (c. 1540). Desenho. Fonte: Acervo do Metropolitan Museum of Art.

Nela, a deusa Belona - como uma Atena Prômacos, a faceta bélica da divindade grega - é retratada com o seu equipamento costumeiro em postura de arremesso. A lateralidade de suas pernas aparece contraposta pela frontalidade do seu tronco parcialmente desnudo e os seus braços, estendidos, executam duas ações simultaneamente: o direito, resetado, prepara o arremesso do seu dardo com uma leveza própria a uma divindade tão digna quanto a deusa da guerra romana, enquanto o esquerdo sustenta a sua égide, provedora do contrapeso necessário para o sucesso da ação.

O desenho divide um fólio do álbum do colecionador francês Pierre-Jean Mariette com outras oito gravuras. Ele também possui uma grande semelhança com outra obra de Andrea Meldola sobre Belona, esta um pouco mais apurada (Figura 4).

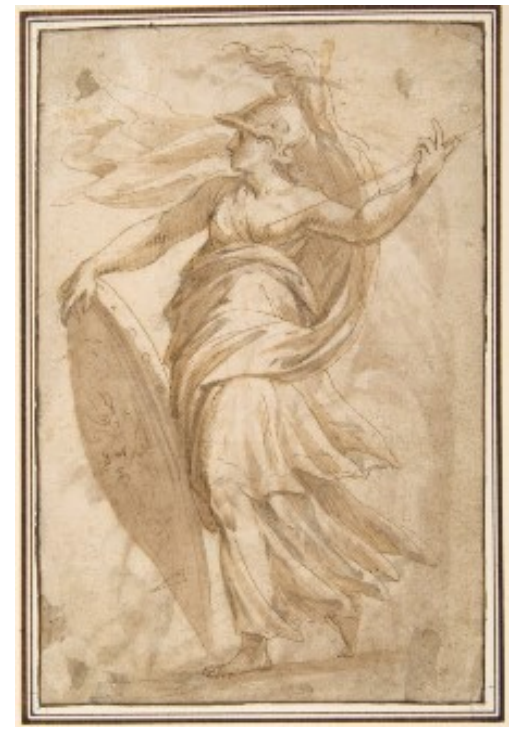

Figura 4 - Andrea Meldola. Bellona (1501-63). Desenho. 15,5 x 10,2 cm. Fonte: Acervo do Metropolitan Museum of Art.

Em ambas as figuras, os cotovelos e punhos estão levemente flexionados, elas têm um pé firme, em contato direto com o chão, uma contraposição ao apoio delicado proporcionado pelo toque da ponta 
do outro. Essa coreografia é emoldurada pela flacidez da crista do elmo de Belona e pela leveza do tecido da sua túnica, que marca o seu flanco quanto e sinaliza a força cinética empreendida no arremesso. Essa plasticidade dos equipamentos da deusa é particularmente interessante, não apenas os movimentos corporais dizem algo, mas também os indumentos que os acompanham.

Essa preocupação com a indumentária tem protagonismo na análise do historiador da arte Aby Warburg desde a sua tese de doutoramento. Nela, Warburg almejou acompanhar

[...] passo a passo como os artistas e seus mentores reconheceram na "Antiguidade" um modelo que exigia intensificar o movimento externo e como se apoiavam em modelos antigos quando precisavam representar elementos acessórios em movimento - principalmente na indumentária e nos cabelos (WARBURG, 2013, p. $3)$.

As roupas e os cabelos são recursos iconográficos capazes de ampliar a ação — e sinalizar a situação - do corpo humano no mundo que o cerca. No caso de Belona, a plasticidade do drapeado indica, precisamente, os vetores das forças que atuam nela e sobre ela. Assim, o casaco repuxado de Norberta não é apenas um pano moldado pela sua agitação. Sob o olhar warburguiano, transforma-se num conjunto de músculos tensionados pelo furor da personagem, ferramentas para auxiliá-la na tarefa hedionda. Também notamos o vestuário atuar como um potencializador da expressão motora das emoções num desenho de Cesare Nebbia sobre a Disputa entre Poseidon e Atena pela possessão de Atenas (Figura 5).

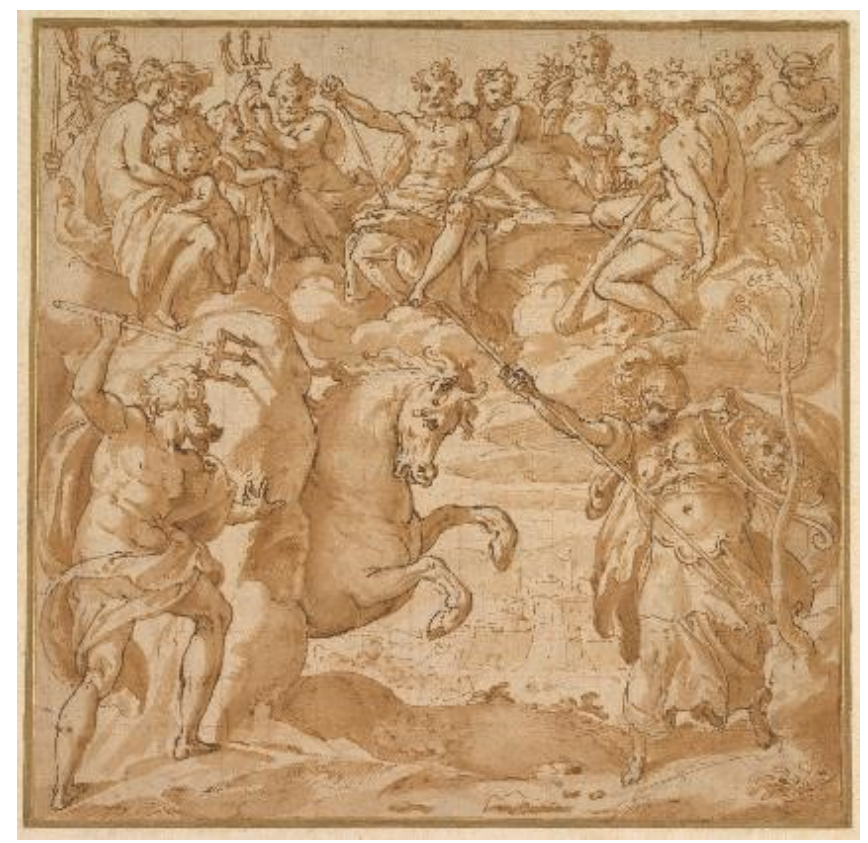

Figura 5 - Cesare Nebbia. A Disputa entre Poseidon e Atena pela posse de Atenas (1570-80). Desenho. 25.9 x 26.4 $\mathrm{cm}$. Fonte: Acervo do Metropolitan Museum of Art.

O poeta Virgílio fala sobre a contenda logo no início do primeiro livro das Geórgicas. Segundo a sua narrativa, a patronagem da Ática seria atribuída à deidade que ofertasse a melhor dádiva aos habitantes da região. Poseidon, então, emergiu um cavalo de uma rocha, enquanto Atena, a vitoriosa, fez brotar a primeira oliveira (VIRGÍLIO, 2006, p. 5-6). Nebbia retratou o momento exato da criação dos dois seres, atentando para a demonstração da pujança neptúnica e da graça minérvica. Enquanto 
o tecido que cobre a nudez do deus dos mares circunda os movimentos vigorosos do seu corpo, a túnica da deusa da sabedoria ressalta um movimento que já vimos anteriormente.

Atena é apresentada tocando com a ponta da sua lança o solo do qual brota a oliveira que lhe concedeu a vitória. A postura da deusa lembra, em certa medida, a dos casos anteriores, ela toca o chão com sua arma num movimento de cima para baixo, projetando o seu corpo para frente, ato que enrijece a sua perna direita, marcada pelo drapeado da sua veste. Contudo, a energia marcial e violenta restrita à obra de Posada e do Pintor de Berlim — presente no movimento das personagens anteriores é transformada aqui em potência criadora. O gesto usado para matar, agora pode soprar vida.

Não apenas as agitações externas captaram o interesse de Aby Warburg, a ambiguidade residente no íntimo das intenções motoras, nas agitações internas, também foi investigada. No seu ensaio sobre a arte flamenga durante o Renascimento, percebeu como Maria Baroncelli, esposa do banqueiro Tommaso Portinari, foi pintada com semblantes diferentes em três retratos produzidos em menos de uma década. Maria aparece primeiro como uma noiva pura e infantil, em seguida, como uma esposa jovem e digna e, no último retrato, transparece a sobriedade e a nobreza da, enfim, Madonna Portinari (MICHAUD, 2013, p. 126-35; WARBURG, 2013, p. 252). É a partir da relação, ou melhor, do conflito dialético entre a polaridade interna e externa do corpo que a categoria "ninfa" surge para auxiliar Warburg no seu ofício.

Assim como os seus objetos de estudo, o historiador da arte hamburguês foi socorrido pelas divindades pagãs, espíritos que o assombravam - e fascinavam — desde a sua tese. A similitude coreográfica do movimento das ninfas também ocupa duas pranchas do inacabado Atlas Mnemosyne, a maior e mais pretensiosa produção do historiador da arte. Os painéis 39, 42, 46 e 47 desvelam a relação existente entre personagens distintas em obras de Domenico Ghirlandaio, Sandro Botticelli, Filippo Lippi e outros, que, na sua maioria, retratam-nas invadindo uma cena cristã com a sua forma pagã. Eles retrataram mulheres "antiquadas" — como se não pertencessem cronicamente àquele lugar - assombradas por um gesto obsessor anacrônico e animado por forças externas. Entretanto, a Ninfa não se limita a uma categoria de adequação do gesto na iconografia, ela opera como um paradigma da postura teórico-metodológica warburguiana, é

[...] um composto indiscernível de originalidade e repetição, forma e matéria. Porém um ser cuja forma coincide pontualmente com a matéria e cuja origem é indiscernível do seu vir a ser é o que chamamos tempo (AGAMBEN, 2012, p. 29).

Transmitidas pela memória histórica, as imagens contêm algo persistente, sobrevivente, à sua existência material, algo que não pode ser encontrado no campo das estruturas arquetípicas alheias às especificidades da mente, mas sim nas suas bifurcações e esquinas mnemônicas. Estas, acolhem as imagens sobreviventes nas suas sarjetas para que renovem as suas forças e ressurjam em outro tempo ou local (DIDI-HUBERMAN, 2013, p. 55). As imagens sobreviventes localizam-se na cisão onde a intenção hesita e permite que uma mesma fórmula floresça sob outras formas, um local que, no estudo da dança, Domênico da Piacenza chamou de fantasmata. Ou seja, "uma pausa não imóvel, mas carregada, ao mesmo tempo, de memória e de energia dinâmica” (AGAMBEN, 2012, p. 26).

O gesto fantasmal de Norberta está fixo na intimidade temporal da cena. Contudo, assim como o vocábulo "fixar" deriva do latim figo, cujo significado pode ser tanto "fixar" quanto "transpassar" ou "perfurar", esse momento de apreensão do retratado não reside em definitivo na imagem em questão. Ele sobrevive através dela numa relação simbiôntica: fornece meios para os artistas solucionarem os problemas do seu ofício na medida em que eles permitam o seu pós-vida. É por esse mecanismo gnosiológico apresentado a nós pelo paradigma nínfico, sistema cuja a sistematização efetiva Warburg nunca finalizou — e talvez não tivesse esse desejo — , que percebemos como um mesmo movimento pode ser dotado de intenções distintas. Como vimos, pensar pela labiríntica proposta 
warburguiana para a história da arte suplanta a busca por afinidades temáticas e situacionais. Circunstância bem delineada, por exemplo, numa tapeçaria sobre a história de Alexandre ${ }^{2}$ ou numa aquarela acerca da morte de Pátroclo ${ }^{3}$.

A existência desses guerreiros indica menos uma "história das inspirações" e mais a utilização, por parte dos artistas, de um mecanismo psíquico autorreferencial, ou melhor, "culturreferencial". A dimensão artística está longe de se enquadrar num "estatuto de pureza" justamente por sua condição estética. Quando um pintor, escultor ou desenhista emprega sua cultura no ato poiético, ele causa agitação no tempo, deixa traços de sua produção nele e dele na sua obra. O tempo não é estático e alvo, mas móvel e permeado por diversas temporalidades, cuja florescência pode ocorrer esporadicamente nos lugares mais insuspeitos. Assim como a Atena de Nebbia subverte o gesto violento do lanceiro num ato de poder criador e civilizatório, vemos também como um ser celestial usa dele para incutir o amor divino na experiência transcendental de Santa Teresa.

As cenas da carmelita tendo o seu peito perfurado pela flecha fulgurante de um Serafim (Figura 6) são recorrentes na arte cristã dos séculos XVII e XVIII. Fenômeno que ocorre muito graças à influência de Vita B. Virginis Teresiae a Iesu Ordinis Carmelitarum (1613).

A série de gravuras de Adriaen Collaert sobre a vida de Teresa de Ávila foi publicada pouco antes da sua beatificação ${ }^{4}$. Encontramos traços da sua influência na península ibérica, onde o culto teresiano tem uma força excepcional, bem como no restante da Europa cristã e nas colônias no Novo Mundo (BORGES, 2006, p. 384-386). Estas últimas nos são de grande interesse, já que nos séculos XVII e XVIII vemos uma profusão de Transverberações afinadas com o trabalho do gravador flamengo. Peru (José Espinoza de los Monteros, 1682), Colômbia (atribuída a Agustín García Zorro de Useche, séc. XVII), Chile (Pintor da Escola de Cuzco, 1690), Equador (Pintor da Escola de Quito, 1653) e México (Figura 6) são locais onde podemos encontrar Teresas amparadas por um anjo e golpeadas no peito por outro, enquanto Cristo supervisiona a cena de braços abertos em meio às nuvens junto do Espírito Santo, este sob a forma de uma pomba branca.

\footnotetext{
${ }^{2}$ Judocus de Vos (tecedor) e Charles Le Brun (projeto). A batalha com o Rei Poro da Índia (c.1700). Disponível em:

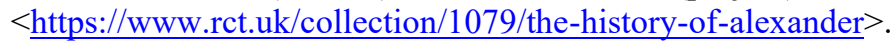

3 José de Madrazo y Agudo. A disputa entre gregos e troianos pelo corpo de Pátroclo (1812). Disponível em:< https://www.museodelprado.es/coleccion/obra-de-arte/la-disputa-de-griegos-y-troyanos-por-el-cuerpo-de/44132e432c22-4bac-9655-741daf5481d6? searchid=3e596d5b-0d71-0259-e3f5-d016963936c2>.

${ }^{4}$ A obra pode ser acessada em: $<$ https://nds.museum-digital.de/index.php? $\mathrm{t}=$ objekt\&oges $=20788 \&$ cachesLoaded $=$ true $>$.
} 


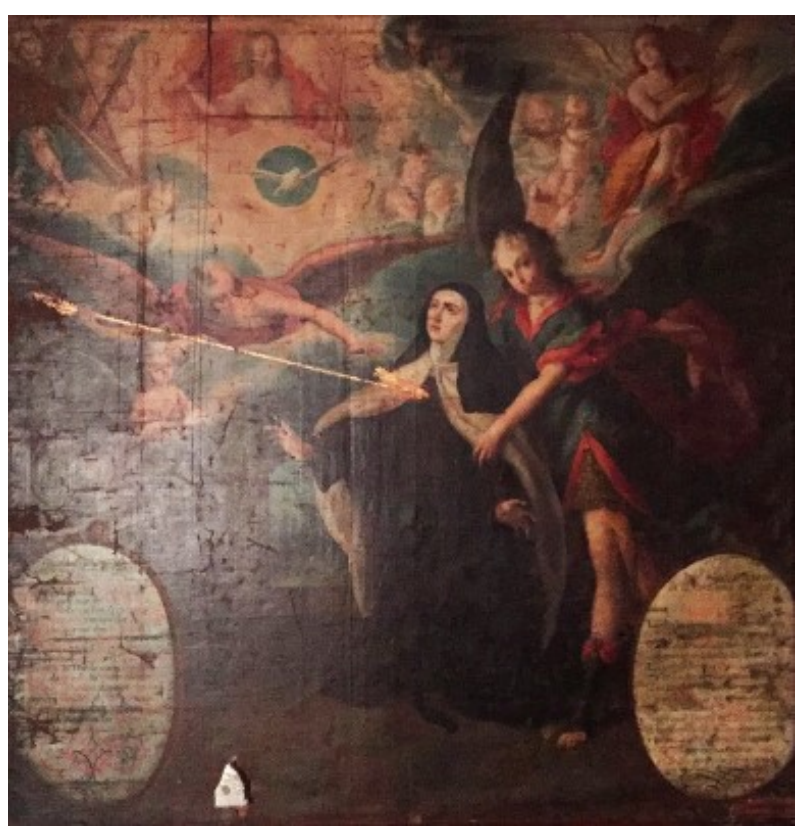

Figura 6 - Juan Rodríguez Juárez. La Trasverberación de Santa Teresa de Jesús (c. 1700-1728). Foto: Víctor Cruz Lazcano. Fonte: Acervo Colonial Art.

O Serafim da tela de Juan Rodríguez Juárez, assim como o da gravura Collaert, reproduz o mesmo gesto do qual repetidas vezes falamos aqui. Embora a sua aparição na cena se dê horizontalmente, o que oculta a parte inferior do seu corpo entre as nuvens celestiais, vemos o seu braço esquerdo estendido em direção à Teresa de Ávila com o intuito de auxiliar o movimento cuidadoso executado pelo direito.

A obra está na sacristia do Templo de Nuestra Señora del Carmen, no coração da capital mexicana, construído na última década do século XVIII, para servir como capela para a Ordem Terceira do Carmo (LAZCANO, 2016, p. 123-124). Não é absurdo cogitar que Posada, numa caminha de pouco mais de 10 minutos da sua oficina até a igreja, por acaso pôde apreciar a pintura para depois valer-se dela ao projetar Norberta. Porém, teria ele de fato feito isso? Provavelmente, não. Até porque, o quadro decora a entrada da sacristia, um espaço pouco frequentado por pessoas não ligadas ao funcionamento do local. Contudo, mesmo que o nosso devaneio fosse embasado em evidências sólidas da inspiração de Posada em tal obra, isso em nada nos ajuda a pensar a viagem do gesto às Américas. Afinal, o simples fato da obra de Juárez e de Posada compartilharem de uma mesma configuração gestual, sem que um tenha conhecimento do outro, já indica a sua presença no continente. Além disso, é provável que o nosso gravador tenha buscado subsídio numa área muito mais próxima de si do que a arte acadêmica do século XVIII, a imprensa.

A influência direta de Juárez sobre Posada é inauferível, mas o mesmo não ocorre no caso do periodismo ilustrado parisiense, barcelonense e novaiorquino. Sabe-se que as grandes publicações estrangeiras conseguiam competir ativamente com as locais na Cidade do México durante os séculos XIX e XX. Além disso, as casas editorias mexicanas faziam uso corriqueiro da reprodução autorizada das gravuras desses semanários tanto que uma das mais famosas revistas ilustradas na época, $L e$ Monde Illustré, possuía uma versão barcelonense com maior penetração no México. Inclusive, na mesma época, Rafael Reyes Spíndola fundou o El Mundo Ilustrado em Puebla, embora a relação direta entre as versões europeias e a mexicana permaneça incerta (GRETTON, 1997, p. 101-102).

O Le Monde Illustré prezava por gravuras e fotogravuras de alta qualidade, uma estratégia editorial voltada para atrair os estratos mais altos da sociedade. Em 1880, uma assinatura anual chegava a custar 24 francos, cerca de 2,5\% da renda das famílias de classe média (GRETTON, 1997, p. 104). É difícil precisar o quão onerosa uma dívida de 24 francos anuais seria no orçamento de um humilde 
gravador mexicano, mas sabemos que Posada recebia 3 pesos por dia trabalhado - um operário da capital mal chegava a 1 peso - (FRANK, 1998, p. 7). Sabemos também que cada edição do concorrente britânico do Le Monde Illustré, o The Illustrated London News, custava 6 pennies em 1860 (cinco pelo impresso e mais um pelo envio), aproximadamente 12 centavos de dólar estadunidense, cujo valor era próximo de 24 centavos de pesos em 1905 (BOJANIC, 2011, p. 11; EDISON, 1987, p. 380). Ou seja, quase um quarto de dia trabalhado para um operário ou algumas horas de trabalho de Posada, uma prática um tanto inviável para a aquisição de referências iconográficas. No entanto, elas estavam ao alcance do principal editor de Posada na capital, Antonio Vanegas Arroyo.

Em 1893, o avô de Blas publica uma gravura de Posada no seu Gaceta Callejera, uma obra baseada em outra de Caton Woodville presente na edição de 21 de outubro do The Illustrated London News (GRETTON, 2018, p. 225). O ilustrador mexicano tinha acesso a esse tipo de periódico graças a seu editor. Arroyo - e, neste caso, Posada - poderia adquirir exemplares dos periódicos europeus também pelo comércio de artigos de segunda mão, onde várias edições eram vendidas a preços módicos depois da sua apreciação por parte dos compradores originais (GRETTON, 1997, p. 104). Nesses locais, Posada pode ter se deparado com outras gravuras de Woodville, como uma sobre a caçada dum javali durante a visita do Príncipe de Gales à Índia (Figura 7).

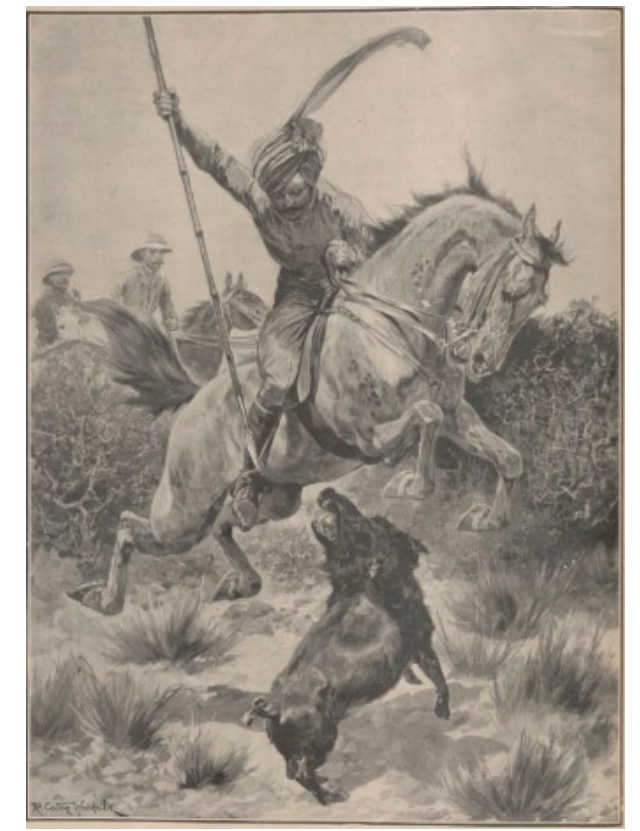

Figura 7 - Caton Woodville. Voyage du Prince de Galles aux Indes - Episode émouvant d'un chasse au sanglier (1906). Gravura. Fonte: Acervo Gallica.

Nela, Woodville retratou o instante anterior ao abate do animal por parte do cavaleiro indiano, que perfura com a sua lança o flanco esquerdo do animal. Este, raivoso, avança em direção ao caçador, num último ato desesperado, com a sua cabeça e patas dianteiras levantadas pela força da sua cabeçada. O cavalo, como um legítimo acessório do pathos motivo, aparece espantado pelo encontro com a besta selvagem. O seu pulo, auxiliado pela agitação da crina e do rabo, ressalta a condição atípica da cena, características exaltadoras da atitude soberana do cavaleiro, que mantém a sua montaria à rédea curta, enquanto desfere o golpe final na sua presa com a perícia e frieza típica da iconografia de caçadas tão desiguais.

Essa relação entre caçador e presa não está restrita a esse tipo de cena. Além do gesto afim da personagem de Woodville - acostumado ao retrato de batalhas e de cavaleiros dos séculos XIX e 
XX — com a de Posada, a mesma formatação física e psicológica aparece no Zeus duma pintura grega sobre a Gigantomaquia (Figura 8).

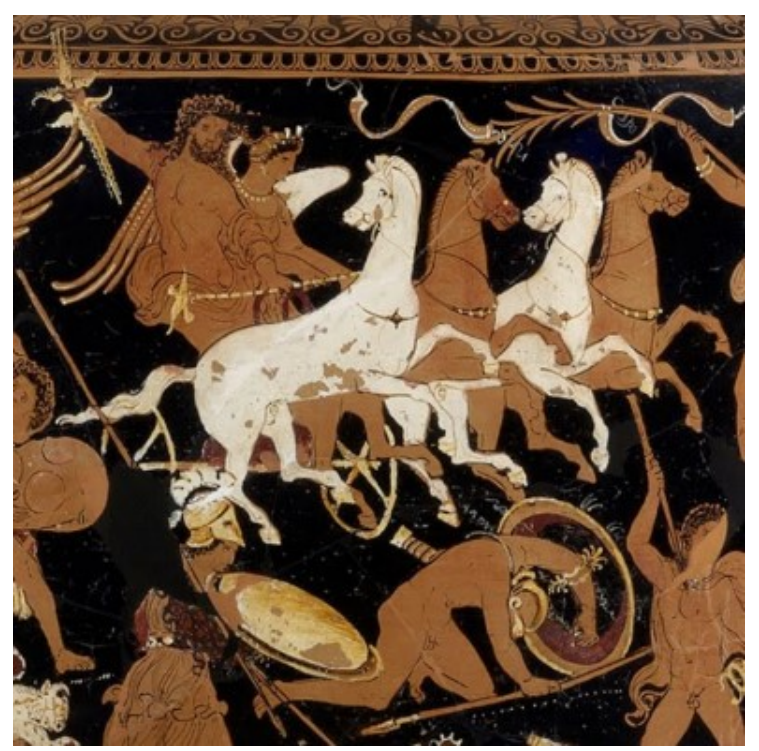

Figura 8 - Pintor do Submundo. Detalhe de Zeus batalhando contra os Gigantes (350 a. C.). Pintura em argila. Fonte: Acervo Staatliche Museen zu Berlin.

No centro da cena sobre a batalha entre Olimpianos e Gigantes pelo domínio do mundo, reconhecemos a postura do lançar dos raios de Zeus presente no cavaleiro indiano. Entretanto, não apenas o ato externo, do arremesso voltado à aniquilação do gigante caído, é semelhante, as pulsões internas também são as mesmas. Portanto, cabe a questão: que semelhança interna existe entre caça dum javali e um dos confrontos centrais da cosmogonia grega? O caçador e o deus pensam o mesmo do confrontante: eles não são rivais, não possuem esse status, são apenas empecilhos ínfimos para os seus objetivos.

Na Biblioteca de Pseudo-Apolodoro, a Gigantomaquia é apresentada como uma disputa já vencida pelo Olimpo. Embora os Gigantes fossem dotados de poderes e força inigualáveis, uma profecia consultada por Zeus assegurara a vitória dos deuses desde que um mortal, no caso, Hércules, participasse da batalha. A cena retratada na cratera grega mostra os confrontos individuais descritos pelo mitógrafo, especificamente, os momentos antes de Zeus derrubar os inimigos com os seus raios para, em seguida, Hércules finalizá-los com as suas flechas (APOLLODORUS, 1921, p. 43-47).

O desejo pela eliminação do outro é uma constante nas cenas de caçadas, batalhas e assassinatos, mas existe ao menos uma diferença suntuosa entre Zeus, o caçador e a jovem mexicana cuja existência não podemos deixar passar desapercebida. Enquanto os atributos viris e controlados dos dois primeiros são exaltados, Posada opta por escancarar os desvios morais de Norberta através da sua postura.

Exploramos de forma recorrente a hipocrisia do gesto na história da arte. Capaz de dissimular a sua intenção, uma mesma ação pode ser tomada por emoções diversas. No entanto, como o caso de Atena e do Serafim, que, respectivamente, gera vida e impele amor, o ato de golpear não é propriamente violento, mas um gesto necessário para um determinado fim. O mesmo não ocorre numa imagem publicada no Le Monde Illustré (Figura 9) seis anos antes de Terrible y verdadera noticia. 


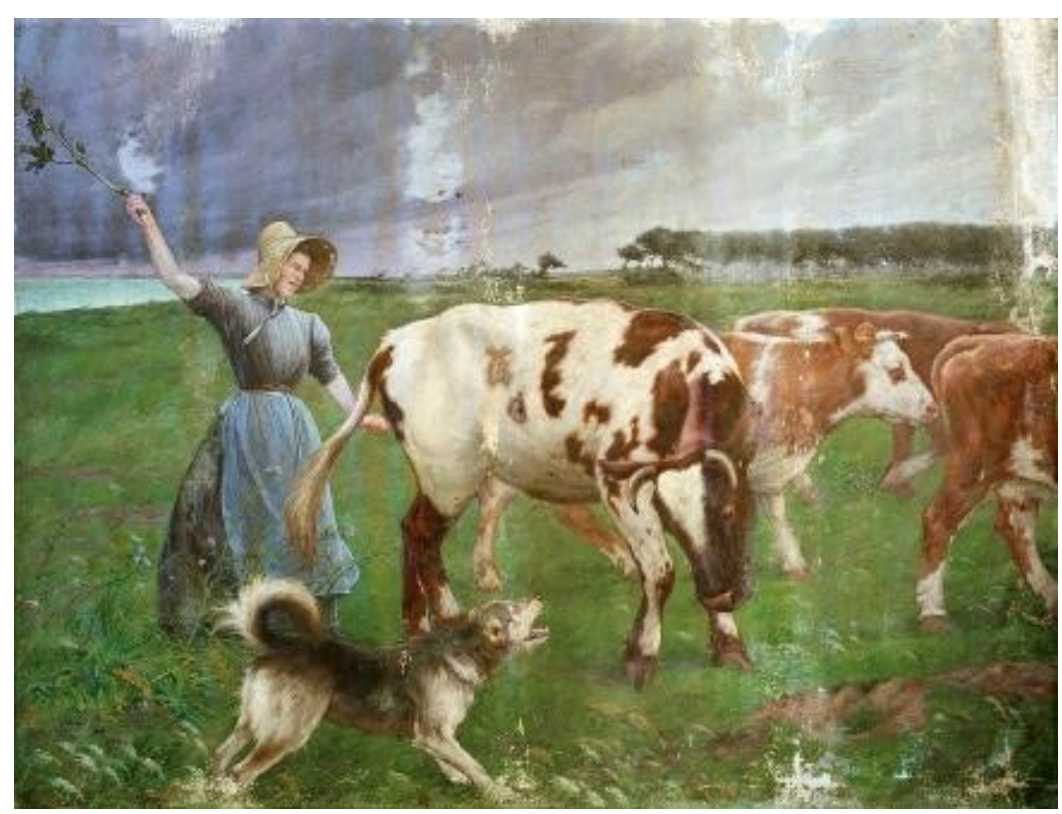

Figura 9 - Jacques Rousseau. L'Approche de l'orage (1902). Óleo sobre tela. 320 x 250 cm. Fonte: Acervo Musée des Augustins.

Na pintura de Jean Jacques Rousseau, uma camponesa aparece numa postura semelhante à da jovem Norberta, mas o que em Posada é usado para expressar um ato violento com uma intenção vil, Rousseau transforma em expressão da preservação de outro ser. Enquanto uma realiza um golpe rápido e fatal, a outra se vale do brandir dum ramo para conduzir o seu rebanho para um local seguro das intemperes climáticas que se aproximam. Com o punho esquerdo cerrado, o direito levantado e um rosto tenso, a mulher luta bravamente contra os ventos que a empurram para frente ao executar a sua tarefa. A fita que prende o seu chapéu à cabeça adere-se ao seu peito, sinal dum avanço em direção aos animais tão tenaz que nem mesmo o vento - capaz de dobrar a grama e as árvores ao fundo da tela - conseguiu inverter a direção da força que atua sobre ela.

Os animas configuram um mundo de conflitos próprio e, como o cavalo de Woodville, atuam como amplificadores dos gestos vitais da camponesa. $\mathrm{O}$ cão confronta a vaca arredia com um latido potente, tensionando o seu corpo numa postura firme que se mantém mesmo sob a ameaça do outro animal. Não se trata duma cena pacífica, a iminência da tormenta mexe com os ânimos das personagens e altera todo o seu sentido, ela transforma as intenções na mesma medida em que o ódio presente em Norberta metamorfoseou-se em tutela conservadora, bem como a desfiguração facial da moça virou apenas um indício de esforço físico na obra francesa.

Ambas as cenas são violentas, embora com propósitos inversos. Uma busca a eliminação do seu alvo por motivos não explicitados na narrativa do corrido — detalhe que acresce brutalidade ao ato enquanto a outra luta pela preservação do rebanho e da sua própria, já que certamente os animais provem parte relevante do sustento da vida no campo. Assim como a decoração duma cratera sobre o mito de Cadmo (Figura 10) concentra no arremesso duma pedra mais do que uma intenção aniquiladora, incutindo também a gênese do patrimônio cultural de Tebas, a chibatada protetiva da camponesa francesa é mais que perpetração, ela carrega a preocupação da sua executora e indica o seu lugar na comunidade em que vive. 


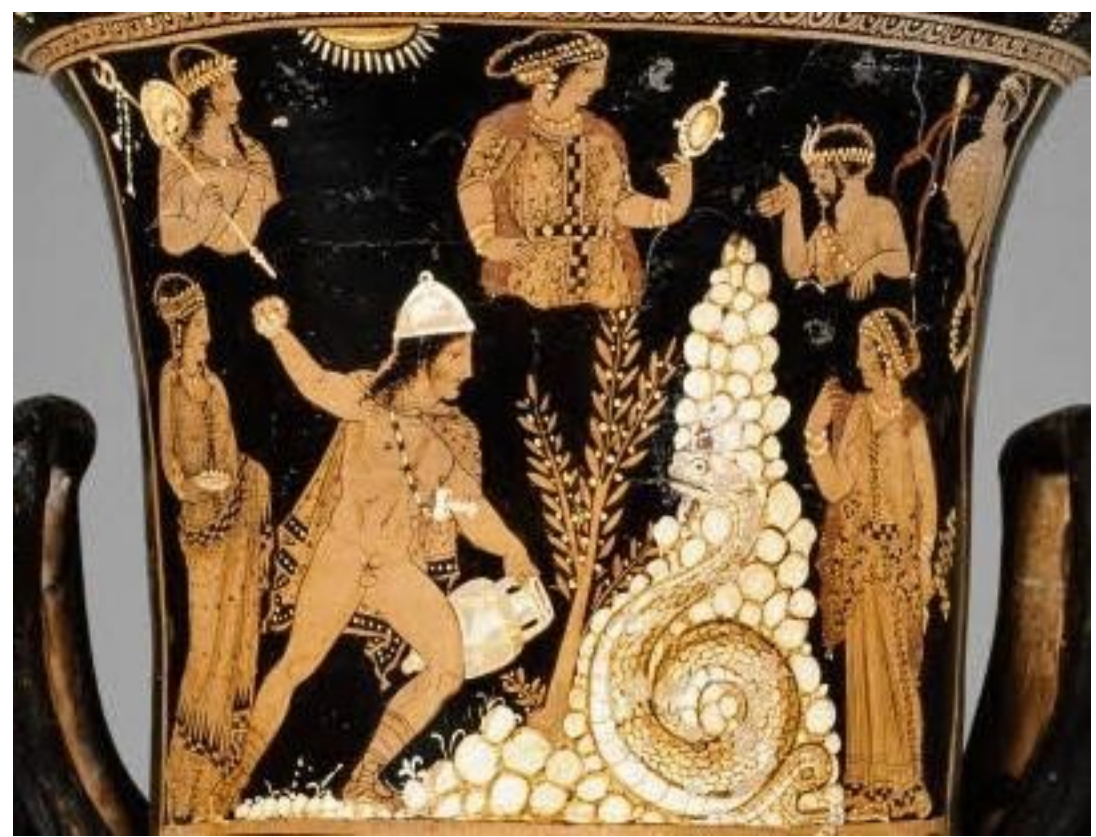

Figura 10 - Pintor da Píton. Cadmo e o Dragão (350-340 a. C.). Pintura em argila. Fonte: Acervo do Louvre.

\section{A originalidade de Posada}

Warburg nos ajuda a pensar Posada na medida em que o seu trabalho não consiste em perguntar "o que foi copiado, ou de que modelo a cópia foi derivada: consiste, em vez disso, em examinar o porquê duma determinada cópia" (BING, 2014, tradução nossa). Não sabemos quais foram as referências de gestos expressivos usadas pelo ilustrador. Porém, os problemas representacionais não são resolvidos somente através de inspirações materiais, mas também por memórias cristalizadas na psiquê. Portanto, como intentamos demonstrar até aqui, o gesto presente na ilustração do corrido de 1910 trata-se dum clichê.

A concepção duma história da arte repleta de clichês talvez seja a grande contribuição de Warburg para o campo. Posada, talvez tenha recorrido de forma consciente aos gestos do passado clássico, mas, mesmo assim, eles sobreviveram ao tempo se esgueirando por entre as frestas da memória, criando cópias totalmente originais de si mesmos nos momentos em que habitaram. Entretanto, essa sobrevivência não é pacífica, Gertrud Bing, numa analogia fluvial que faz jus às de Walter Benjamin, nos fala que

A tradição, para Warburg, não era um córrego que carregava os eventos e as pessoas. As influências não são uma questão de aceitação passiva, mas exigem um esforço de ajuste, 'eine Auseinandersetzung' [uma disputa], como Warburg disse, do presente com o passado (BING, 1965, p. 310, tradução nossa).

Bing, citando Warburg, preferiu não traduzir "eine Auseinandersetzung", uma escolha segura dada aos possíveis equívocos que isso poderia causar. Georges Didi-Huberman adaptou, numa leitura impecável, a expressão para "uma dialética tensa" (DIDI-HUBERMAN, 2013, p. 76). Tensa, porque nesse rio da tradição, do tempo, do progresso técnico da modernidade, que nos empurra para o futuro redentor - e, no caso de Rivera, para uma arte popular mexicana - surgem forças antiquadas determinadas a tomar o fluxo para si. 
O observador atento, situado não na fonte, mas no vale (BENJAMIN, 1987, p. 21), nota que essa disputa não se limita ao campo estético, falar sobre o tempo warburguiano é falar sobre a memória. Carlo Ginzburg, na sua investigação de processos inquisitoriais, notou como o paganismo rasteja para luz da modernidade sob o véu das lembranças dos que não sabem que sabem (GINZBURG, 2012, 1. 13). Essas vidas imortais etéreas não necessitam de monumentos e testemunhos, pois habitam, ou assombram, o campo de experiência humana, são inesquecíveis (BENJAMIN, 2013, p. 78).

A existência dessa esquizofrenia das lembranças conscientemente imemoriáveis, da luta entre o Apolo-técnico e o Dioniso-mágico, remete-nos à afirmação de Rivera quanto à originalidade de Posada. A obra de Posada foi original? A resposta não poderia ser mais bipolar: não e sim. Não, porque outras obras rompem a pureza urdida por Rivera, porque ele usou dos periódicos estrangeiros como referência. Mas também sim, na medida em que "a arte contemporânea será tanto mais eficaz quanto mais se orientar em função da reprodutibilidade e, portanto, quanto menos colocar no seu centro a obra original" (BENJAMIN, 1987, p. 181). Posada fez para os fantasmas que o assombravam morada nas suas gravuras, espaços onde "qualquer vibração de sua alma é aceita, desenvolvida e aproveitada como expansão de seus limites intelectuais" (WARBURG, 2013, p. 126). Ou seja, ele foi original na medida em que usou da cópia, mas o uso de Rivera é puramente mitológico e propagandístico. Tanto que o seu colega, Jean Charlot, duvida da sua amizade com Posada. Segundo ele, quando apresentado às matrizes das gravuras de Posada, Rivera disse que nunca tinha as visto, algo improvável caso as afirmações do muralista fossem verdadeiras (TYLER, 1973, p. 7). Coisa que não muda o fato de Posada ter sido usado como uma referência para projetar uma arte popular nacional para um governo desejoso por incluir-se no curso do rio do devir moderno.

\section{Considerações Finais}

Não existe demérito no uso que José Guadalupe Posada fez de outras produções artísticas, seja ele proposital ou não. Muito pelo contrário, a sobrevivência das fórmulas de pathos corre ao lado da história da arte e esse é justamente o valor da proposta warburguiana, uma proposta que atenta para os saltos da memória e que pode mostrar determinadas incongruências narrativas.

A maquinação de Rivera para que Posada ocupasse o lugar do pai fundador duma arte popular mexicana tem parte do seu funcionamento desvelado pela iconologia de Warburg, cuja operação não permite a omissão do pós-vida contestador dos discursos estruturantes modernos. Na construção do muralista, Posada era tomado com um Apolo virtuoso, mas, para nós, ele mostra-se como Dioniso, o deus renascido, o subversor de qualquer ordem. Não é possível pensar através de Warburg concebendo estruturas rígidas e ordenadoras, como as estabelecidas no texto de 1930.

Terrible y verdadeira noticia, por sua vez, longe de ser um modelo anedótico de aplicação dum suposto método é um exercício de modelagem do paradigma warburguiano com o intuito de analisar um discurso através da iconologia. $\mathrm{O}$ uso dessa imagem em específico mostra-se fortuito graças à amplitude referencial alcançada, um atributo que não se limita a ela, mas que pode ser um empecilho caso o paradigma seja usado em alguma outra obra, pois nem tudo sobrevive à força do tempo e à plasticidade da memória.

Por fim, cabe destacar o escopo das forças que pode apoderar-se dum mesmo gesto. A configuração corporal humana não é nada genérica, cada tensão e torção é um vestígio da motivação interna e externa que agita certa personagem. Pois, o uso de determinadas características para a expressão emotiva é justamente o que faz a faceta da originalidade maculada vir à tona. 


\section{Referências}

AGAMBEN, Giorgio. Ninfas. São Paulo: Hedra, 2012.

. O príncipe e o sapo: O problema do método em Adorno e Benjamin. In: Infância e história: destruição da experiência e origem da história. Tradução de Henrique Burigo. Belo Horizonte: Editora UFMG, 2008.

APOLLODORUS. The Library. Tradução: James George Frazer. Londres: William Heinemann, 1921.

BENJAMIN, Walter. Origem do drama trágico alemão. Tradução: João Barreto. Belo Horizonte. Autêntica, 2020.

BENJAMIN. Escritos sobre mito e linguagem. São Paulo: Editora 34; Duas Cidades, 2013.

. Passagens. Tradução de Irene Aron e Cleonice Paes Barreto Mourão. Belo Horizonte e São Paulo: Editora UFMG e Imprensa Oficial do Estado de São Paulo, 2009.

. O surrealismo. O último instantâneo da inteligência européia. In: _. Magia e técnica, arte e política. Ensaios sobre literatura e história da cultura. Trad. de Sérgio Paulo Rouanet. São Paulo: Brasiliense, 1987. v.1.

. A obra de arte na era de sua reprodutibilidade técnica. In: . Magia e técnica, arte e política. Ensaios sobre literatura e história da cultura. Trad. de Sérgio Paulo Rouanet. São Paulo: Brasiliense, 1987. v.1.

BING, Gertrud. A. M. Warburg. Journal of the Warburg and Courtauld Institutes, v. 28, 1965, p. 299-313. Disponível em: <http://www.jstor.org/stable/750675>. Acesso em: 20 out. 2020.

. Aby M. Warburg by Gertrud Bing. Engramma, 2014. Tradução de Elizabeth Thomson.

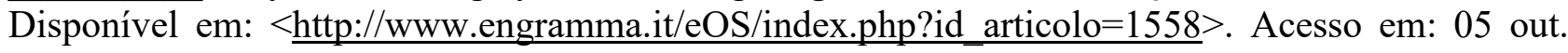
2020.

BORGES, Célia Maia. A Representação Iconográfica de Santa Teresa: mística e plástica na Península Ibérica na época barroca. In: Atas do IV Congresso Internacional do Barroco Ibero-Americano, Ouro Preto e Mariana, 2006, p. 379-389. Disponível em: < https://www.upo.es/depa/webdhuma/areas/arte/4cb/pdf/C\%C3\%A9lia\%20Maia\%20Borges.pdf $>$

Acesso em: 10 out. 2020.

BOJANIC, Antonio. Final Years of the Silver Standard in Mexico: Evidence of Purchasing Power Parity with The United States. História Econômica \& História de Empresas, n. XIV, v. 1, mai., 2011, p. 5-34. Disponível em: $<$ https://mpra.ub.uni-muenchen.de/45535/1/MPRA paper 45535.pdf $>$ Acesso em: 21 out. 2020.

EDER, Rita. Muralismo mexicano: modernidad e identidad cultural. In: BELLUZZO, Ana Maria de Moraes (org). Modernidade: vanguardas artísticas na América latina. São Paulo: UNESP. 1990, p. 100-120. 
DIDI-HUBERMAN, Georges. A imagem sobrevivente: história da arte e tempo dos fantasmas segundo Aby Warburg. Rio de Janeiro: Contraponto. 2013.

. Diante do tempo: história da arte e anacronismo das imagens. Tradução: Vera Casa Nova e Márcia Arbex. Belo Horizonte: Editora UFMG, 2015.

EDISON, Hali. Purchasing Power Parity in the Long Run: A Test of the Dollar/Pound Exchange Rate (1890-1978). Journal of Money, Credit and Banking, n. 19, n. 3, aug., 1987, p. 376-387. Disponível em: $<$ https://www.jstor.org/stable/1992083?seq=1>. Acesso em: 20 out. 2020.

FRANK, Patrick. Posada's broadsheets: Mexican popular imagery, 1890-1910. Albuquerque: University of New Mexico Press, 1998.

GINZBURG, Carlo. História Noturna: Decifrando o Sabá. Tradução: Nilson Moulin Louzada. São Paulo: Companhia das Letras, 2012.

GRETTON, Tom. European Illustrated Weekly Magazines, c. 1850-1900. A Model and a CounterModel for the Work of José Guadalupe Posada. Anales del Instituto de Investigaciones Estéticas, v. XIX, n. 70, mar, 1997, pp. 99-125, Distrito Federal, México.

Edgy Encounters in North Africa and the Balkans: R. C. Woodville's Pictures of Conflict-Zone Life for the Illustrated London News, 1880-1903. In: CLARKE, Joseph, HORNE, John. (Eds.) Militarized Cultural Encounters in the Long Nineteenth Century. War, Culture and Society, 1750-1850. London: Palgrave Macmillan. 2018.

LAZCANO, José Víctor Manuel Cruz. Hermanos de sangre y religión: Oligarquías y orden del Carmen en Nueva España borbónica. Dissertação (Mestrado em Cultura Virreinal), Universidad del Claustro de Sor Juana, México, 2016.

MARCH, Gladys; RIVERA, Diego. Diego Rivera: mi arte, mi vida. Cidade do México: Editorial Herrero, 1963.

MICHAUD, Philippe-Alain. Aby Warburg e a imagem em movimento. Rio de Janeiro: Contraponto, 2013.

RIVERA, Diego. José Guadalupe Posada. In: TOOR, Frances et al. Monografía. Las obras de José Guadalupe Posada. Grabador Mexicano. Ciudad de México: Editorial RM, 2012.

TARBELL, Frank. Centauromachy and Amazonomachy in Greek Art: The Reasons for Their Popularity. American Journal of Archaeology. Vol. 24, No. 3, jul.-set., 1920, pp. 226-231.

TOOR, Frances. Advertencia. In: TOOR, Frances et al. Monografía. Las obras de José Guadalupe Posada. Grabador Mexicano. Ciudad de México: Editorial RM, 2012.

TYLER, Ron. Posada's Mexico. In: (Ed.). Posada's Mexico. Washington: U.S. Government Printing Office, 1979.

VASARI, Giorgio. The lives of the artists. Tradução: Julia Conaway Bondanella e Peter Bondanella. Oxford: Oxford Press, 1998. 
. Le vite dei più eccellenti pittori, scultori e architetti. Áquila: REA Edizioni. 2011. E-

book.

VIRGÍLIO. Georgics. Tradução: Peter Fallon. Oxford: Oxford University Press, 2006.

WINCKELMAN, Johann Joachim. The History of Ancient Art. v. 1. Tradução: Henry Lodge. Boston: James R. Osgood and Company, 1873.

. On the Imitation of the Painting and Sculpture of the Greeks. In: IRWIN, David (Ed.). Writings on art. London: Paidon, 1972.

WARBURG, Aby. A renovação da Antiguidade pagã: Contribuições científico-culturais para a história do Renascimento europeu. Tradução: Markus Hediger. Rio de Janeiro: Contraponto, 2013. 